\title{
The Generation of Thermostable Fungal Laccase Chimeras by SCHEMA-RASPP Structure-Guided Recombination in Vivo
}

\author{
Ivan Mateljak, ${ }^{\dagger}$ Austin Rice, ${ }^{\ddagger}$ Kevin Yang, ${ }^{\ddagger}$ Thierry Tron, ${ }^{\S}$ and Miguel Alcalde ${ }^{* \dagger}{ }^{\dagger}$ \\ ${ }^{\dagger}$ Department of Biocatalysis, Institute of Catalysis, CSIC, Cantoblanco, 28049 Madrid, Spain \\ ${ }^{\ddagger}$ Division of Chemistry and Chemical Engineering, California Institute of Technology, CALTECH, Pasadena, California \\ 91125-4100, United States \\ ${ }^{\S}$ Aix Marseille Université, Centrale Marseille, CNRS, iSm2 UMR 7313, 13397 Marseille, France
}

Supporting Information

ABSTRACT: Fungal laccases are biotechnologically relevant enzymes that are capable of oxidizing a wide array of compounds, using oxygen from the air and releasing water as the only byproduct. The laccase structure is comprised of three cupredoxin domains sheltering two copper centers-the $\mathrm{T} 1 \mathrm{Cu}$ site and the $\mathrm{T} 2 / \mathrm{T} 3$ trinuclear $\mathrm{Cu}$ cluster-connected to each other through a highly conserved internal electron transfer pathway. As such, the generation of laccase chimeras with high sequence diversity from different orthologs is difficult to achieve without compromising protein function-

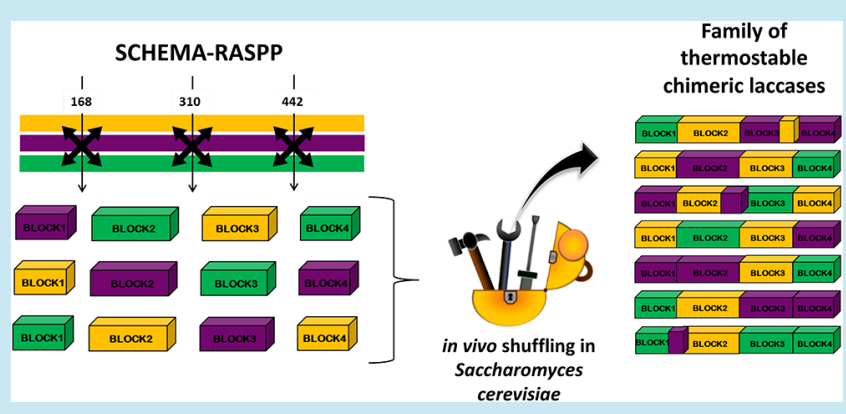
ality. Here, we have obtained a diverse family of functional chimeras showing increased thermostability from three fungal laccase orthologs with $\sim 70 \%$ protein sequence identity. Assisted by the high frequency of homologous DNA recombination in Saccharomyces cerevisiae, computationally selected SCHEMARASPP blocks were spliced and cloned in a one-pot transformation. As a result of this in vivo assembly, an enriched library of laccase chimeras was rapidly generated, with multiple recombination events simultaneously occurring between and within the SCHEMA blocks. The resulting library was screened at high temperature, identifying a collection of thermostable chimeras with considerable sequence diversity, which varied from their closest parent homologue by 46 amino acids on average. The most thermostable variant increased its half-life of thermal inactivation at $70{ }^{\circ} \mathrm{C} \mathrm{5}$-fold (up to $108 \mathrm{~min}$ ), whereas several chimeras also displayed improved stability at acidic $\mathrm{pH}$. The two catalytic copper sites spanned different SCHEMA blocks, shedding light on the recognition of specific residues involved in substrate oxidation. In summary, this case-study, through comparison with previous laccase engineering studies, highlights the benefits of bringing together computationally guided recombination and in vivo shuffling as an invaluable strategy for laccase evolution, which can be translated to other enzyme systems.

$\mathrm{L}$ accases are versatile biocatalysts that belong to the group of blue multicopper containing oxidases. They harbor one $\mathrm{T} 1 \mathrm{Cu}$ ion, where the oxidation of a wide range of substrates takes place, and a T2/T3 trinuclear $\mathrm{Cu}$ cluster, where molecular oxygen is reduced to water, while the whole protein structurally is arranged into three cupredoxin domains. Laccases have generated considerable interest in biotechnology, and they have been used in organic synthesis and in various industrial fields, from bioremediation, food and textiles, pulp-biobleaching, biofuel cells, and biosensor development. ${ }^{1,2}$ Laccases are widely distributed in fungi, higher plants, and bacteria, performing a variety of biological activities. An important advantage of fungal laccases over their plant and bacterial counterparts is the high-redox potential at the $\mathrm{T} 1 \mathrm{Cu}$ site. As such, high-redox potential fungal laccases (HRPLs) exhibit strong catalytic activity, oxidizing a broad spectrum of compounds with high-redox potential, including high-redox potential mediators, upon which medium- and low-redox potential laccases hardly act. ${ }^{3}$ For years, the engineering of HRPLs has attracted much attention, mostly taking advantage of a palette of library creation methods coupled to screening assays as part of different directed evolution campaigns. ${ }^{4}$ These approaches have been aimed at enhancing heterologous expression and activity against different substrates, or at augmenting the stability of the enzyme in non-natural environments like organic solvents, ionic liquids, and human blood, to name but a few.

While laboratory evolution from individual fungal laccase templates have been successful, attempts to generate laccase chimeras from different orthologs have been less productive. For example, when we tried to combine two evolved HRPL versions-engineered for secretion in yeast-from basidiomycetes $\mathrm{PM} 1^{5}$ and Pycnoporus cinnabarinus ${ }^{6}$ via in vitro and in vivo DNA shuffling, only a limited set of functional chimeras was obtained, with poor sequence diversity. That is, the chimeras were mostly composed of the highest-expressing parent with few crossover events in the mature protein. ${ }^{7}$ Similarly, laccase

Received: December 4, 2018

Published: March 21, 2019 
chimeras designed by in vivo shuffling of several isoforms in S. cerevisiae (Lac1, Lac2, Lac3, and Lac5 from Trametes $s p$. strain C30) generated a library prone toward the Lac3 parent due to its stronger expression in this heterologous host. ${ }^{8}$ Moreover, preliminary rational design of chimeras was attempted with two isoforms (Lccl and Lcc4) from the basidiomycete Lentinula edodes expressed in tobacco By- 2 cells, connecting the $\mathrm{N}$-terminus of Lcc1 to the C-terminus of Lcc4 (i.e., producing only one crossover point). ${ }^{9}$ Due to the complex laccase structure, with two $\mathrm{Cu}$ centers connected to each other through a highly conserved HisCysHis tripeptide of $12 \AA$ that regulates the flow of electrons between the two catalytic sites, it is difficult to obtain significant sequence diversity from chimeragenesis experiments without endangering protein function. ${ }^{10,11}$

SCHEMA structure-guided protein recombination is a computational method that is extremely useful to create chimeric proteins with large sequence diversity. This approach has been applied to cytochrome P450 monooxygenases, $\beta$ lactamases, cellulases, arginases, and channel rhodopsins, most notably to improve thermostability, but also substrate specificity, $\mathrm{pH}$ dependence, and membrane localization. ${ }^{12-20}$ In structure-guided recombination, the crossover locations are selected in order to minimize disruption to the 3-dimensional protein structure, as measured by the library-average SCHEMA energy. The SCHEMA energy $(E)$ is the average number of pairwise interactions in a recombination library that are not present in any of the library parents. ${ }^{21}$ To complement the SCHEMA method, Arnold's group also developed the RASPP (Recombination as Shortest Path Problem) algorithm to solve the problem of generating libraries that minimize $(E)$ for a range of $(m)$ - the average number of mutations in a library relative to the closest parent, enabling functional chimeras to be created with greater sequence diversity. ${ }^{22}$

Here, we present a family of chimeric laccases obtained by SCHEMA-RASPP structure-guided recombination combined with in vivo shuffling in S. cerevisiae. Computationally designed SCHEMA blocks were introduced into $S$. cerevisiae where they were shuffled and assembled in vivo with the help of flanking overlapping areas specifically conceived at the crossover locations. The library of functional chimeras was designed from three high-redox potential fungal laccase orthologs, and it was screened at high temperatures. A family of chimeras was obtained with high sequence diversity derived from recombination events both between and within SCHEMA blocks, showing notably improved thermostability. Moreover, several of the chimeric laccases displayed modified activity preferences for particular substrates and enhanced stability at acidic $\mathrm{pH}$. The library construction method that combined SCHEMARASPP with in vivo DNA recombination in yeast is discussed in depth, as are its implications in protein chimeragenesis.

\section{RESULTS AND DISCUSSION}

Departure Point: Parental Laccases. Heterologous functional expression of HRPLs is difficult to achieve., ${ }^{4,3}$ Indeed, the complex post-translational modifications (Nterminal and/or C-terminal processing, glycosylation) that laccases undergo along the secretory pathway, as well as the precise coordination of four copper ions at two distant sites, have precluded their functional expression in standard prokaryotic hosts like Escherichia coli or Bacillus subtilis. In eukaryotic hosts, some fine-tuning is typically needed to obtain reasonable levels of secretion. In previous work, we achieved adequate expression in $S$. cerevisiae of two HRPLs from basidiomycetous PM1 (PM1L) ${ }^{5}$ and Pycnoporus cinnabarinus $(\mathrm{PcL})^{6}$ by laboratory evolution. In both cases secretion was improved from scratch by switching the native laccase signal peptide to the $\alpha$-factor prepro-leader from $S$. cerevisiae $(\alpha 1-\alpha 89)$ and subjecting the corresponding fusions to iterative rounds of random mutagenesis and recombination. Through this approach, the secretion variants OB-1 (secreted at $8 \mathrm{mg} / \mathrm{L}$ and carrying the mutations $\mathrm{V}[\alpha 10] \mathrm{D}-\mathrm{N}[\alpha 23] \mathrm{K}-$ $\mathrm{A}[\alpha 87] \mathrm{T}-\mathrm{V} 162 \mathrm{~A}-\mathrm{H} 208 \mathrm{Y}-\mathrm{S} 224 \mathrm{G}-\mathrm{A} 239 \mathrm{P}-\mathrm{D} 281 \mathrm{E}-\mathrm{S} 426 \mathrm{~N}-$ $\mathrm{A} 461 \mathrm{~T}$ ) and $3 \mathrm{PO}$ (secreted at $2 \mathrm{mg} / \mathrm{L}$ and carrying the mutations $\mathrm{A}[\alpha 9] \mathrm{D}-\mathrm{F}[\alpha 48] \mathrm{S}-\mathrm{S}[\alpha 58] \mathrm{G}-\mathrm{G}[\alpha 62] \mathrm{R}-\mathrm{E}[\alpha 86] \mathrm{G}-$ N208S-R280H-N331D-D341N-P394H) were obtained from PM1L and PcL, respectively (the mutations lying in the evolved $\alpha$-factor prepro-leaders- $\alpha^{\mathrm{PM1}}$ and $\alpha^{\mathrm{PcL}}$ - are underlined). In another study, the medium-redox potential Lac3 laccase isoform from the basidiomycete Trametes sp. strain C30 was expressed in $S$. cerevisiae at $2 \mathrm{mg} / \mathrm{L}$ by attaching the invertase leader sequence from yeast. ${ }^{24}$ In the current study, OB-1, 3PO, and Lac3 were chosen as the departure points for laccase chimeragenesis. These orthologs shared roughly $70 \%$ sequence identity at the protein level, and they had a redox potential at the $\mathrm{T} 1 \mathrm{Cu}$ site ranging from 680 to $790 \mathrm{mV} v \mathrm{~s}$ NHE (Normal Hydrogen Electrode), as well as a half-life of thermal inactivation between 8 and $22 \mathrm{~min}$ (the half-life $\left(t_{1 / 2}\right)$ is defined as the incubation time at $70{ }^{\circ} \mathrm{C}$ that will reduce postincubation enzyme activity at room temperature by $50 \%$, Table 1). To maximize parental enzyme secretion prior to

Table 1. Comparison of Parental Laccases

\begin{tabular}{ccccccc} 
& \multicolumn{3}{c}{ identity $(\%)$} & & & \\
\cline { 2 - 4 } laccase & OB-1 & Lac3 & 3 PO & $\begin{array}{c}\text { amino } \\
\text { acids }\end{array}$ & $\begin{array}{c}t_{1 / 2}{ }^{a} \\
(\mathrm{~min})\end{array}$ & $\begin{array}{c}E_{\mathrm{T} 1}(\mathrm{mV}) v s \\
\mathrm{NHE}\end{array}$ \\
OB-1 & & 69.96 & 72.98 & 496 & 22 & 740 \\
Lac3 & 69.96 & & 68.61 & 501 & 16 & 680 \\
3PO & 72.98 & 68.61 & & 497 & 8 & 790
\end{tabular}

${ }^{a}$ The values of half time $\left(t_{1 / 2}\right)$ were obtained by measuring residual activity after enzyme incubation at $70{ }^{\circ} \mathrm{C}$.

SCHEMA-RASPP, we designed 9 fusions to consider all the possible combinations of the different $\alpha$-factor prepro-leaders $\left(\alpha^{\text {native }}, \alpha^{\mathrm{PM1}}\right.$, and $\left.\alpha^{\mathrm{PcL}}\right)$ for each of the three parental laccases, ${ }^{25}$ Supplementary Figure S1. The invertase leader sequence was not included in this benchmarking as previous studies on PM1L and PcL discouraged its use. The evolved $\alpha^{\mathrm{PcL}}$ provided the strongest expression irrespective of the laccase to which it was attached, and therefore, it was used with the three parental variants to express and screen the SCHEMA library.

SCHEMA-RASPP Library Design and Recombination in Vivo. An ideal enzyme chimeragenesis experiment using SCHEMA is based on a three-step approach called "sample, model, and predict": ${ }^{26}$ step 1, SCHEMA family design; step 2, synthesis of a representative subset of SCHEMA sequences that are expressed functionally and characterized biochemically; and step 3, the prediction, through regression, of those chimeric sequences with the most desirable traits for their subsequent synthesis. This strategy has proved to be successful for many recombinant intracellular enzymes expressed in bacteria. However, the results for extracellular enzymes are less encouraging, as a subset of chimeras may not be easily secreted, compromising the representation of the SCHEMA 


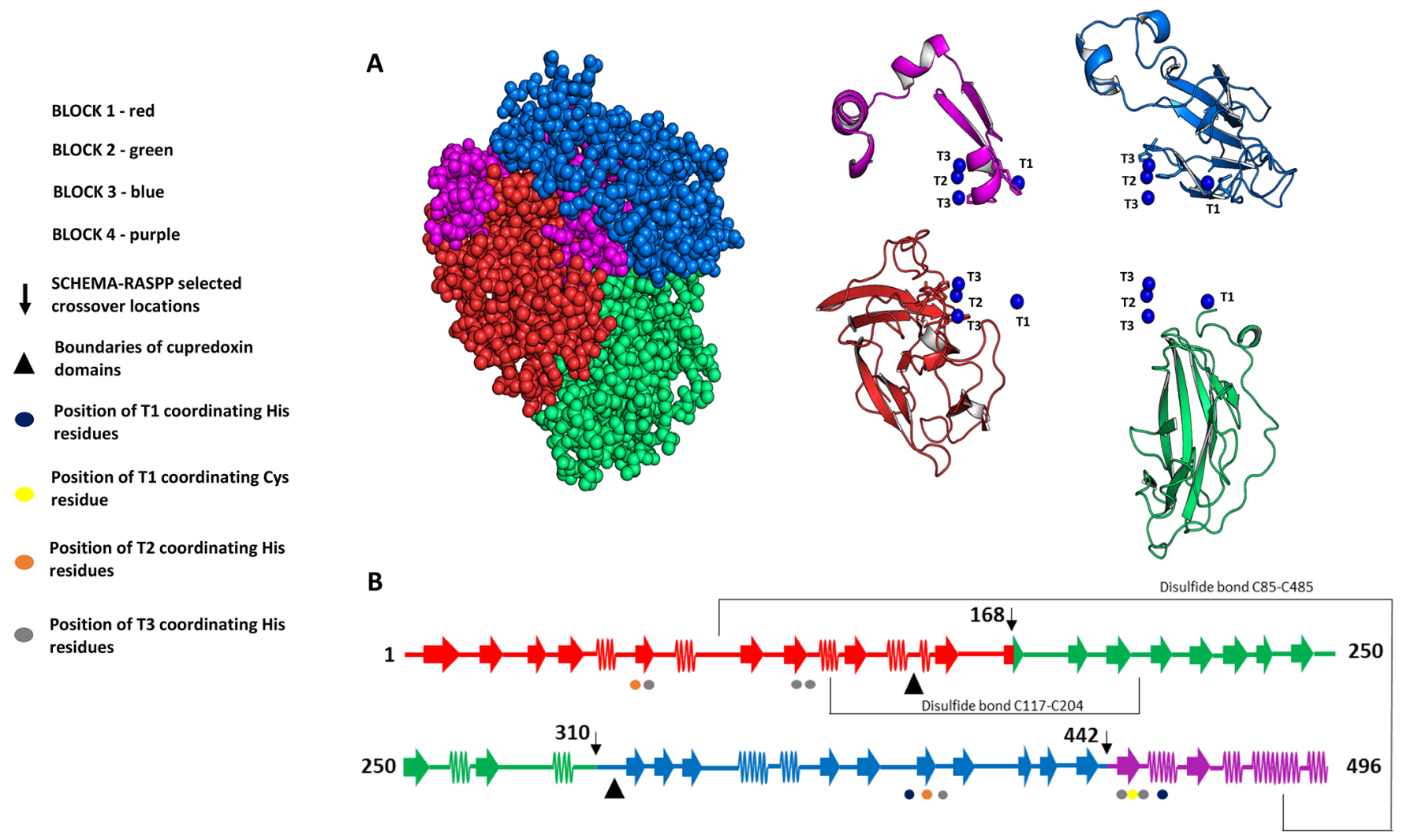

Figure 1. SCHEMA recombination library design. (A) The laccase structure is depicted as spheres and as a cartoon. Copper atoms are highlighted as blue spheres. The SCHEMA building blocks are shown in different colors. Model of the OB-1 laccase based on the high resolution structure of Trametes trogii laccase (PDB entry 2HRG), sharing 96\% sequence identity to OB-1. (B) Secondary structure of SCHEMA blocks highlighted in different colors.

blocks in the sample. ${ }^{16}$ In the case of our heavily glycosylated HRPLs, their poor secretion and complex structural architecture are attributes not well-suited to reliable linear regression modeling, which led us to SCHEMA library construction and screening. In previous studies, the combinatorial recombination of SCHEMA-defined gene fragments had been accomplished through time-consuming and expensive in vitro methods or DNA synthesis. ${ }^{27}$ However, and even considering the progressive price drop in DNA synthesis, there is still an urgent need for reliable cloning and recombination methods, especially when one is faced with the challenge of screening thousands of clones per day. ${ }^{28,29}$ For years, our favorite recombination strategy for eukaryotic genes has been based on the high-frequency homologous DNA recombination of $S$. cerevisiae, through which we have engineered different enzymes for a variety of processes. ${ }^{23}$ As such, we took advantage of the recombination machinery of S. cerevisiae to shuffle and clone the SCHEMA blocks in vivo in a drive to enrich the functional diversity of the mutant library while maximizing the throughput of library generation.

We first modified the SCHEMA-RASPP algorithm by writing two scripts to give us additional information in order to select crossover points in areas of higher sequence identity between the three laccase orthologs that can then be used for recombination in yeast (see Supporting Information). These scripts score the crossover points and potential libraries based on the identity around the crossover point, where larger numbers represent more identical residues around the crossover point (see Materials and Methods for details). As a protein scaffold for SCHEMA-RASPP calculations, we used a homology model of OB-1 based on the high-resolution structure of Trametes trogii laccase (PDB entry 2HRG, with a sequence identity of $96 \%$ vs OB-1), a laccase formed by three cupredoxin $\beta$-barrel domains (D1, D2, and D3) that shares $96 \%$ sequence identity with $\mathrm{OB}-1$. The $\mathrm{T} 2 / \mathrm{T} 3 \mathrm{Cu}$ cluster is located at the interface between D1 and D3, whereas the $\mathrm{T} 1 \mathrm{Cu}$ site and the HisCysHis electron transfer pathway are situated in D3. The substrate binding site is formed by residues belonging to D2 and D3, and the overall structure of the enzyme is stabilized by two interdomain disulfide bridges.

Taking into account this structural information, we ran the SCHEMA-RASPP algorithm in an attempt to find crossover points between the parental laccases that minimize protein structure disruption in the resulting recombination library. We designed several computational libraries of 4 to 7 SCHEMA blocks, with $(E)$ ranging from 8 to 12 and $(m)$ from 58 to 65 , Supplementary Table S1. To maintain a good balance between transformation efficiency and recombination, we chose a library with 4 blocks for in vivo cloning in yeast (three recombination events between blocks and two to link the blocks to an expression vector). This library strikes a good balance between homology at the crossover points, modulation of the $\mathrm{Cu}$ binding sites and overall structural conservation. The library selected had $(m)$ and $(E)$ values of 58 and 8 , respectively, with defined crossover positions at residues 168 , 310 , and 442 (numbered according to the mature OB-1 laccase protein: see Figure 1 for a structural overview of this library). Our parent laccases contain three $\beta$ sandwiches belonging to the corresponding cupredoxin domains. The N-terminal block 1 contains the first cupredoxin domain and the structurally 


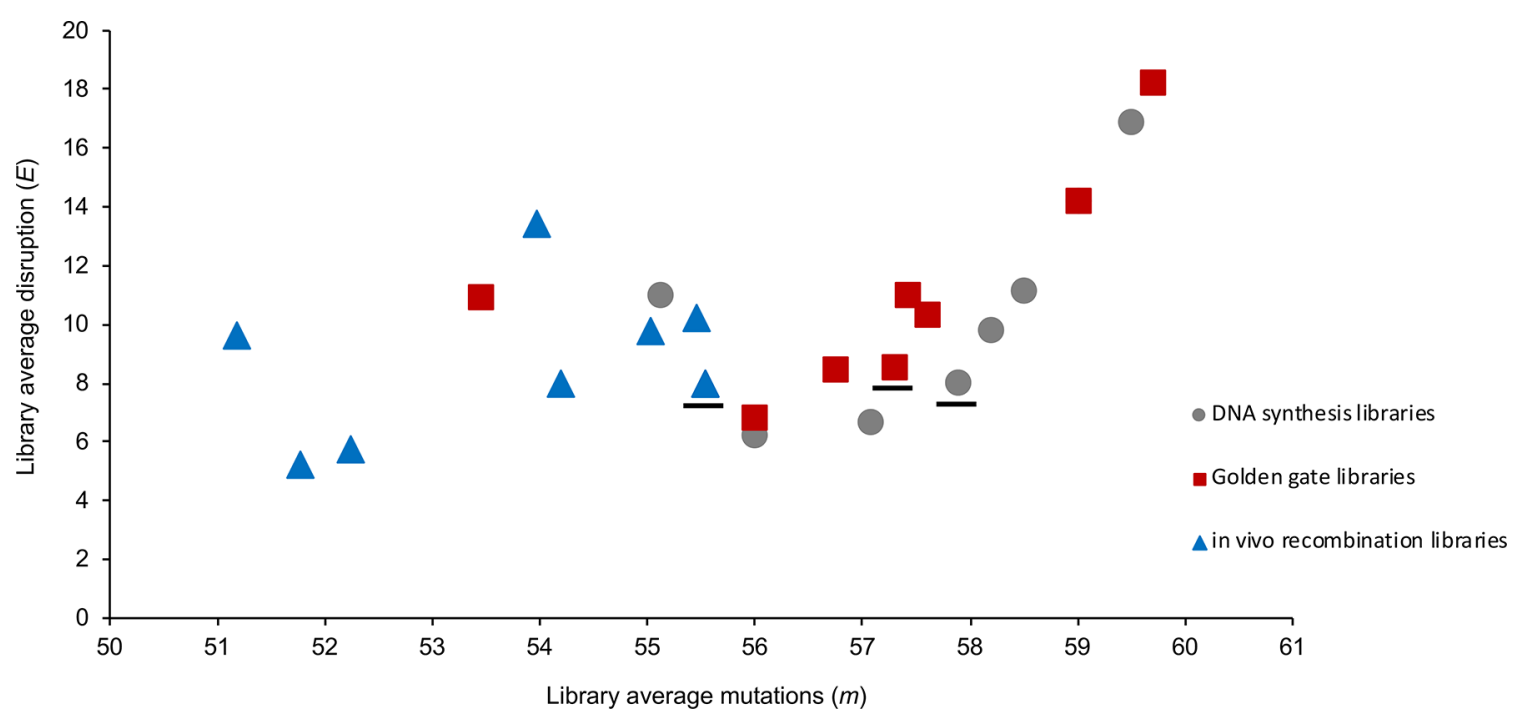

Figure 2. Comparison of library construction methods on SCHEMA disruption energy and mutation rate. $E$ and $m$ values calculated for each of 8 libraries designed for assembly through 3 different methods: in vivo recombination (blue triangles), golden gate assembly (red squares), and direct DNA synthesis (gray circles). Selected library used in the present study constructed by three different methods is underlined. In general, in vivo recombination decreases the library average number of mutations (by 4 mutations) and the disruption energy obtainable through recombination (by $1.7 \mathrm{E}$ values). Golden gate assembly (where the parent sequences are not mutated but the crossover points are slightly shifted away from RASPP-calculated optimal sites) slightly decreases the library average number of mutations (by 0.5 mutations) and slightly increases disruption energy (by $0.5 E$ values). Comparative $E$ and $m$ values are relative to the synthetic library.

adjacent loop and $\beta$-strands of the second domain; block 2 contains the remainder of the second cupredoxin domain; blocks 3 and 4 make up the third cupredoxin domain, with block 4 also containing the C-terminal $\alpha$ helix that interacts with block 1 . Although the coordination spheres of both the $\mathrm{T} 1 \mathrm{Cu}$ and $\mathrm{T} 2 / \mathrm{T} 3 \mathrm{Cu}$ cluster were not near any designed crossover point, the SCHEMA design was selected to modulate both $\mathrm{Cu}$ binding sites. Indeed, blocks 3 and 4 participate in the first coordination shell of the $\mathrm{T} 1 \mathrm{Cu}$ ion, with two coordinating His and one Cys residues. The trinuclear T2/ $\mathrm{T} 3 \mathrm{Cu}$ cluster is coordinated by six His residues distributed within SCHEMA blocks 1, 3 and 4, Figure 1. Finally, the HisCysHis tripeptide, which physically connects the $\mathrm{T} 1 \mathrm{Cu}$ ion and the $\mathrm{T} 2 / \mathrm{T} 3 \mathrm{Cu}$ cluster, is responsible for intramolecular electron transfer and it is located in the last and smallest fragment.

When checking the multiple sequence alignment of the parental types, there appeared to be only a few regions with sufficient homology for the in vivo assembly of SCHEMA blocks, including the crossover point 422 between blocks 3 and 4. Despite the new SCHEMA algorithm, the sequence identity between the three laccase templates at the first two crossover locations (168 and 310 positions) was not high enough to guarantee reliable recombination events in $S$. cerevisiae, Supplementary Figure S2. Indeed, on average, $40 \mathrm{bp}$ of homology at a given crossover location is necessary to facilitate the in vivo splicing between blocks without jeopardizing the yeast transformation efficiency, which is necessary to generate a mutant library with enough clones to screen. ${ }^{30}$ Consequently, we decided to modify the parental sequences using OB-1 as a template given its higher thermostability (Table 1), such that there is 30 to $40 \mathrm{bp}$ of homology at each crossover point selected by SCHEMA-RASPP, Supplementary Figure S3. For the first crossover site, only one residue in Lac3 and two residues in $3 \mathrm{PO}$ were substituted, whereas at the second crossover site, we needed to change three residues in Lac3 and five in 3PO. In the third crossover site, homology between the three parents was good enough so that no further mutations were included. These parental mutations reduced the library average number of mutations introduced through chimeragenesis (the $m$ value) to 56 and the $E$ value remained at 8 . Through this strategy, we simply transformed yeast with the pool of individual SCHEMA blocks along with the linearized plasmid. ${ }^{31}$ Accordingly, one-pot repair and cloning was carried out in vivo to generate a complete set of laccase chimeras. The success of this cloning strategy was noteworthy, as thousands of clones per transformation reaction were recovered even though five recombination events were necessary to close the full autonomously replicating plasmid. Given that we shuffled 4 blocks between three orthologs, 81 possible hybrid clones $\left(3^{4}\right)$ can be theoretically created. In the library, this number could even be higher due to the potential of $S$. cerevisiae to shuffle DNA within SCHEMA blocks (see below). In order to validate our library construction method by in vivo recombination, we compared it with in vitro methods used in SCHEMA studies (golden gate assembly and direct DNA synthesis). Eight libraries were designed in silico for all the three methods aimed at assessing the effect on $E$ and $m$ values. As expected, when increasing the homology of the parents, both $E$ and $m$ slightly decreased using the in vivo recombination approach, Figure 2. This small decrease is compensated in terms of library creation simplicity (avoiding ligation steps), and it adds the possibility of including beneficial intrablock recombination events (see below).

Sequence Analysis and Thermostability of Laccase Chimeras. A general precondition for an enzyme to be exploited industrially is its thermal stability. Therefore, engineering thermostable fungal laccases with the capacity to withstand harsh industrial reaction conditions is particularly desirable. $^{2,32}$ In addition, such stable laccases provide promising departure points for future evolutionary endeavors, since they will be better able to tolerate destabilizing mutations 


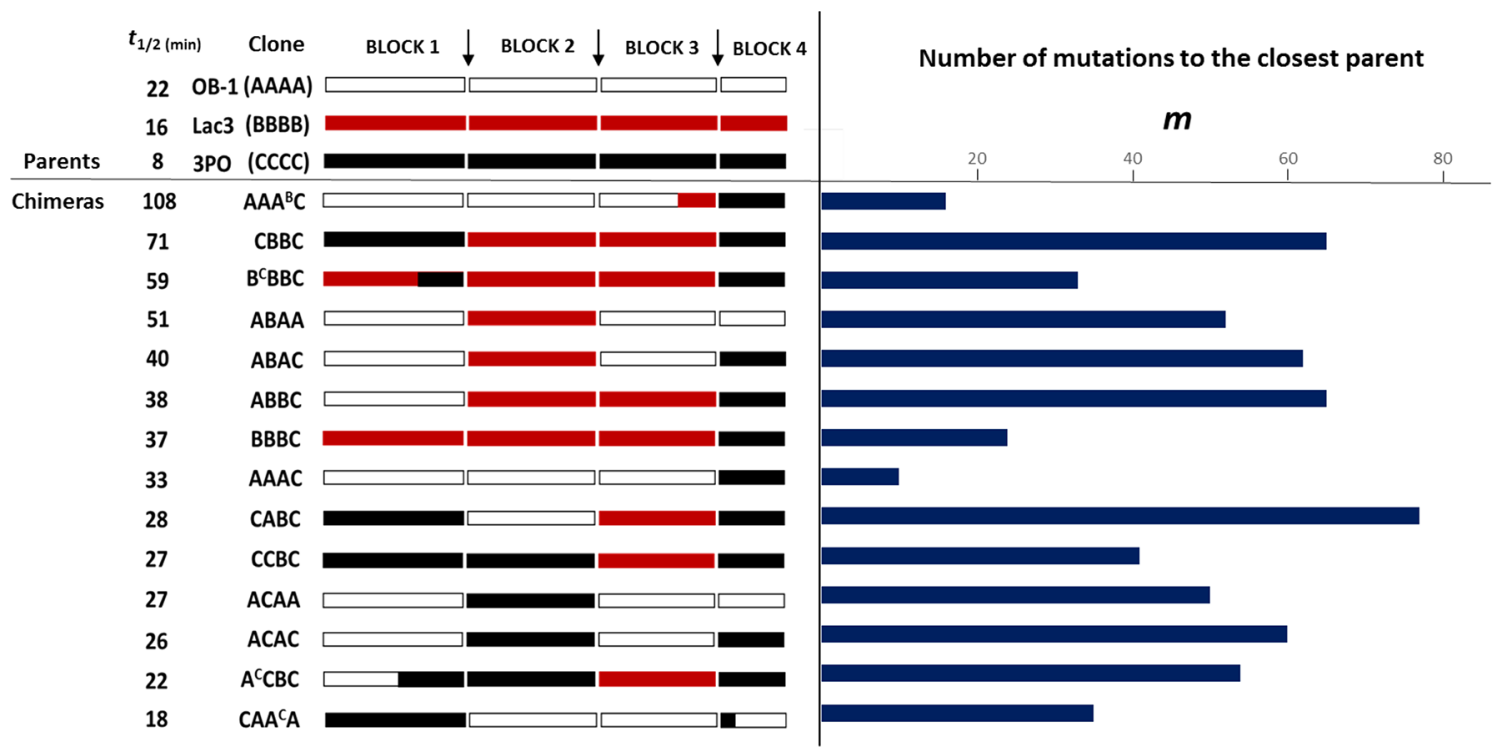

Figure 3. Family of thermostable chimeric laccases. Sequence diversity is highlighted by colors, where white stands for AAAA (OB-1), red for BBBB (Lac3), and black for CCCC (3PO). The blue bars show the amino acid differences between the corresponding chimera and its closest homologue. The half-life inactivation time $\left(t_{1 / 2}\right)$ of chimeric laccases at $70{ }^{\circ} \mathrm{C}$ is shown in the left column. Appropriate enzyme supernatant dilutions in $20 \mathrm{mM}$ bis-tris buffer $\mathrm{pH} 6.0$ were incubated at $70^{\circ} \mathrm{C}$. Aliquots $(50 \mu \mathrm{L})$ were removed after $5,15,25,35,55,75,95$, and $120 \mathrm{~min}$, chilled on ice for $10 \mathrm{~min}$ and further incubated at room temperature for at least $5 \mathrm{~min}$. Subsequently, the residual activity (initial rates) was determined in an 2,2'-azino-bis(3-ethylbenzothiazoline-6-sulfonic acid) (ABTS) assay (100 $\mathrm{mM}$ sodium phosphate/citrate buffer $\mathrm{pH} 4.0$ and 3 $\mathrm{mM} \mathrm{ABTS}$ ), and it was expressed relative to the ABTS activity at room temperature. Each value is the average of three independent experiments.

required for novel activities. ${ }^{33}$ We screened the chimeric library for thermostability using a high-throughput assay we developed previously and applied to other fungal ligninases expressed by yeast. ${ }^{34}$ Around 1000 clones were screened by measuring their residual activity after heat shock at $70{ }^{\circ} \mathrm{C}$ for $10 \mathrm{~min}$. After three consecutive rescreenings, 14 unique thermostable laccase chimeras were isolated and characterized (Figure 3). This set of chimeras had high sequence diversity that varied from their closest parent by between 10 to 77 mutations. On average, 46 amino acid substitutions were introduced from the closest parent sequence and these chimeras were named according to their fragment composition: A representing SCHEMA blocks for OB-1 (AAAA), B for Lac3 (BBBB), and C for 3PO (CCCC), with noncomputed blocks indicated in superscript. Five chimeras $\left(\mathrm{AAA}^{\mathrm{B}} \mathrm{C}, \mathrm{ABAC}, \mathrm{ABBC}, \mathrm{CABC}\right.$, and $\mathrm{A}^{\mathrm{C}} \mathrm{CBC}$ ) were composed of SCHEMA blocks from all three parental types. Moreover, chimeras $A A A^{B} C$ and $A^{C} C B C$, together with $\mathrm{B}^{\mathrm{C}} \mathrm{BBC}$ and $\mathrm{CAA}{ }^{\mathrm{C}} \mathrm{A}$, underwent further recombination within the SCHEMA blocks due to stochastic in vivo shuffling, thereby producing functional enrichment of the mutant library. The broad sequence diversity generated by the in vivo SCHEMA-RASPP guided recombination was much higher than that found in any previous attempt of laccase chimeragenesis. $^{7-9}$

Of the 14 thermostable laccases identified, 12 exhibited a higher $t_{1 / 2}$ of thermal inactivation at $70{ }^{\circ} \mathrm{C}$ relative to the most stable parent, OB-1 (Figure 3). Although $3 \mathrm{PO}$ was the least thermostable parent, when the composition of the chimeras was examined, the last block of $3 \mathrm{PO}$ (C4) appeared to be strongly stabilizing in this context, participating in $85 \%$ of the thermostable laccases, Supplementary Figure S4. Block 4 is the smallest of the SCHEMA blocks, representing only $11 \%$ of the protein sequence, although it does contain roughly $40 \%$ of all the $\alpha$-helix forming residues, which seem to be crucial for the overall protein stability. Conversely, the $\mathrm{C} 3$ block from 3PO was not observed in any of the thermostable variants selected, suggesting a destabilizing effect that it may contribute to the low stability of 3PO, Supplementary Figure S4. Of all the chimeras, $\mathrm{AAA}^{\mathrm{B}} \mathrm{C}$ showed a striking 5-fold increase in thermostability relative to the most stable parent, OB-1 (AAAA). The $\mathrm{AAA}^{\mathrm{B}} \mathrm{C}$ chimera had a $t_{1 / 2}$ of thermal inactivation at $70{ }^{\circ} \mathrm{C}$ of $108 \mathrm{~min}(77 \mathrm{~min}$ longer than $A A A C)$, yet the only difference between the $\mathrm{AAA}^{\mathrm{B}} \mathrm{C}$ and AAAC chimeras is the substitution of a 18 residue segment in block A3 from OB-1 with the final region of block B3 from Lac3. This modification was the result of an intrablock (nondesigned) in vivo homologous recombination, introducing six additional mutations into block 3 (relative to A3): V424T, N426S, S429T, P430D, R439T, D441N (Supplementary Figure S5). In our laccase structural model, residues Val424 and Asn426 are located near the interface of cupredoxin domains 2 and 3, Ser429 and Pro430 at the turn of a long solvent exposed loop, and Arg439 and Asp441 are solvent exposed residues near the loop between two $\beta$-strands and the crossover point between SCHEMA blocks 3 and 4 . Neither the transferability nor the importance for the stability of this region was predicted computationally. Only the fact that we performed a DNA shuffling in vivo enabled the discovery of this exceptionally stable laccase chimera.

We found stabilizing relationships between clones BBBC, $\mathrm{B}^{\mathrm{C}} \mathrm{BBC}$, and $\mathrm{CBBC}$ in our chimeric collection that might also affect the patterns of activity (see below). These chimeras were comprised exclusively of Lac3 and 3PO blocks, the two least stable parents. By accumulating more of $3 \mathrm{PO}$ in block 1 , a gradual increase in thermostability was detected, from $t_{1 / 2}=37$ min to $t_{1 / 2}=71 \mathrm{~min}$.

All three clones contained the stabilizing $\mathrm{C} 4$ block from $3 \mathrm{PO}$, which improved $\mathrm{BBBC}$ clone stability 2.3 -fold over the closest and most stable parent, in this case Lac3. The incorporation a 36 amino acid segment of $3 \mathrm{PO}$ at the end of 


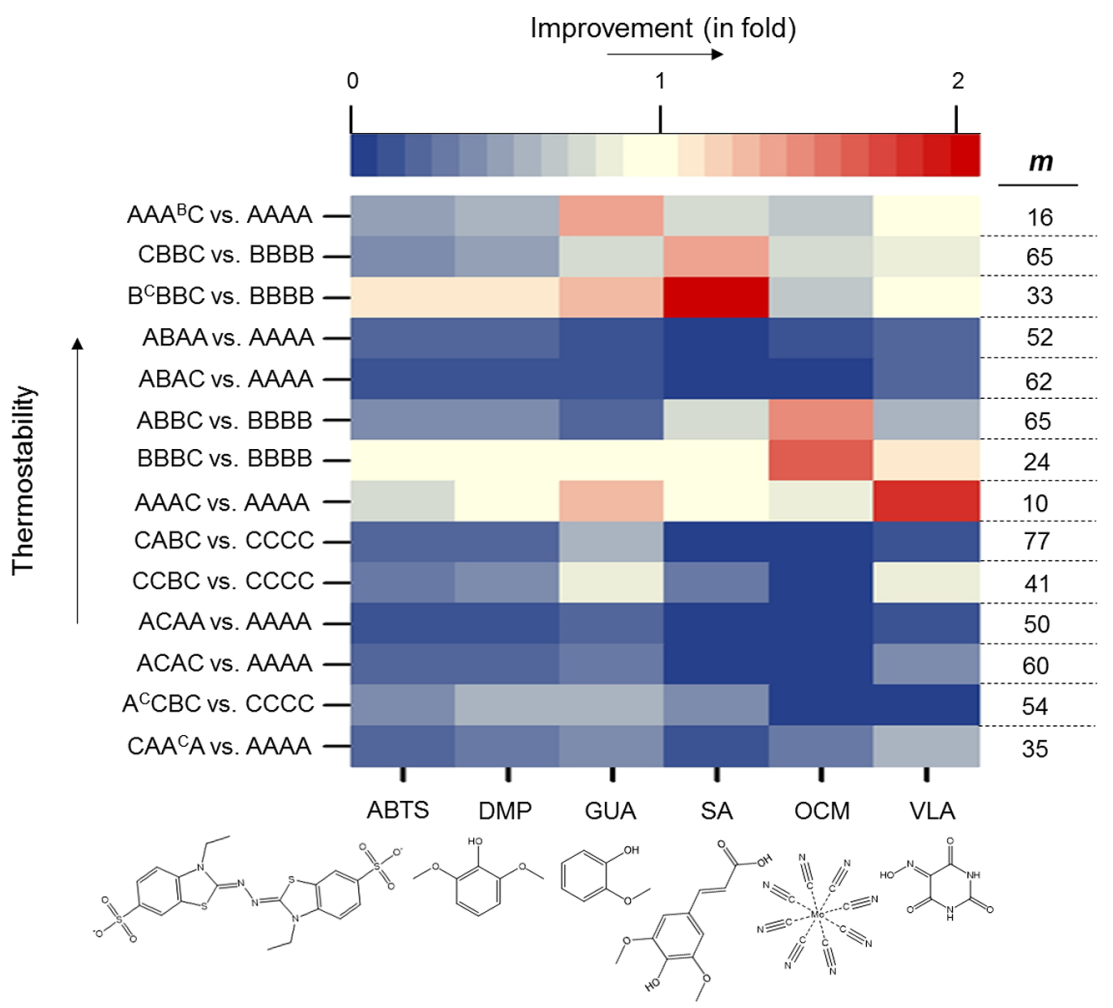

Figure 4. Activity of the chimeras on different substrates. Heat map of the total activity of the 14 chimeric laccases relative to the parental type. The parental type is defined as the closest homologue for each chimera and the chimeras are organized by increasing thermostability. The number of mutations relative to the closest parent $(m)$ is highlighted on the left column. Supernatants of the chimeras and parental types $(20 \mu \mathrm{L})$ were mixed with $180 \mu \mathrm{L}$ of $100 \mathrm{mM}$ sodium phosphate/citrate buffer $\mathrm{pH} 4.0$, and the corresponding substrates: $3 \mathrm{mM}$ ABTS, 3 mM 2,6-dimethoxyphenol (DMP), $10 \mathrm{mM}$ guaiacol (GUA), $2 \mathrm{mM}$ potassium octacyanomolbdate (OCM), $0.25 \mathrm{mM}$ sinapic acid (SA), and $20 \mathrm{mM}$ violuric acid (VLA). The reactions were performed in triplicate, and the laccase activity was normalized to the closest parental type.

block 1 further introduced 9 mutations in the $\mathrm{B}^{\mathrm{C}} \mathrm{BBC}$ clone resulting in an overall 3.7-fold improvement of the stability. Finally, when the whole of block 1 was swapped between Lac3 and $3 \mathrm{PO}$ in the CBBC chimera, we observed an overall 4.4fold increase in thermostability. In summary, several segments of the least stable parent $3 \mathrm{PO}$ can positively contribute to protein stability in chimeras.

Activity Pattern of Thermostable Laccase Chimeras. We assessed the preliminary oxidation capacity of thermostable chimeras using six laccase substrates of different chemical nature and redox potential. Initial rates of laccase chimeras estimated in fresh supernatants are arranged in a heat map to compare them to their closest homologue, Figure 4. Globally, many variants were found to have a total activity lower than their closest homologues, for the majority of the substrates tested (blue tints dominate the map). The C2 block clearly appears to diminish the total activity, as the four chimeras containing block 2 of $3 \mathrm{PO}$ acted weakly on all the substrates tested. Notably, the three most thermostable clones $\left(\mathrm{AAA}^{\mathrm{B}} \mathrm{C}\right.$, $\mathrm{CBBC}$ and $\mathrm{B}^{\mathrm{C}} \mathrm{BBC}$ ) maintained or even improved their activity for some of the substrates. Chimeras BBBC and $\mathrm{ABBC}$ displayed $\sim 1.7$ - and 1.5-fold enhanced activity when oxidizing the high-redox potential substrate potassium octacyanomalybdate IV (OCM, a metal transition complex used as a laccase redox mediator). Similarly, clone AAAC displayed a 1.9-fold improvement in the oxidation of another high-redox potential mediator, violuric acid (VLA). In the case of low-redox potential mediator sinapic acid (SA), the chimera $\mathrm{B}^{\mathrm{C}} \mathrm{BBC}$ exhibited a 2-fold enhancement, while $\mathrm{CBBC}$ also performed 1.4-fold better than its closest parent. Curiously, we did not detect any improvements for other low-redox potential compounds like phenolic 2,6-dimethoxyphenol (DMP), guaiacol (GUA), or the nonphenolic mediator 2,2'-azinobis(3-ethylbenzothiazoline-6-sulfonic acid) (ABTS), although with GUA a modest increase could be observed with some variants.

To explore the activity patterns observed among the chimeric laccases, we established a structural alignment of the parental sequences surrounding the $\mathrm{T} 1 \mathrm{Cu}$ site, Figure 5. Previously, several amino acid positions of the catalytic cavity (162-164, 205, 263, 264, 331, 336, 390-392, and 455) have been shown to influence substrate oxidation in other highredox potential laccases sharing 96 to $98 \%$ sequence identity to OB- $1 .{ }^{35,36}$ Moreover, we recently enhanced the redox potential of the OB-1 laccase by computational and directed evolution methods, showing that the residue at position 458 is involved in both the binding and the redox potential of the $\mathrm{T} 1 \mathrm{Cu}$ site (unpublished material). Interestingly, all four SCHEMARASPP designed blocks participated to a greater or lesser extent in sculpting the catalytic cavity of the chimeras. The 162-164 loop belongs to block 1, whereas the highly conserved Asp205 (harboring the first acceptor proton of the redox process) and the 263-264 loop are part of block 2 . There are two conserved Phe at positions 331 and 336 in block 3 , together with loop 390-392 in the vicinity of the T1Cu site, while the $\alpha$ helix that carries the conserved Ala458 and His 455 (the first electron acceptor) is within block 4, Figure 5. Therefore, the combination of variations in these segments could be used to rationalize the different substrate oxidation patterns observed among the chimeras. 


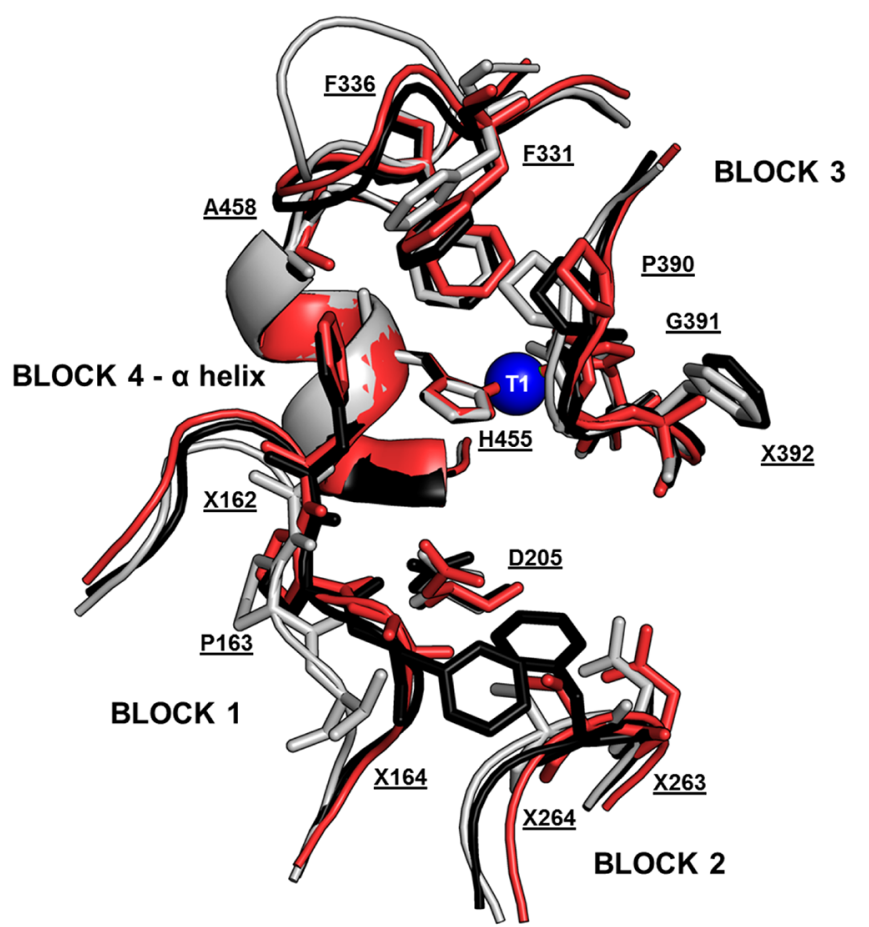

\begin{tabular}{|c|c|c|c|c|}
\hline & BLOCK 1 & BLOCK 2 & BLOCK 3 & BLOCK 4 \\
\hline $\mathrm{OB}-$ & $\begin{array}{ccc}162 & 163 & 164 \\
A & P & T\end{array}$ & $\begin{array}{ccc}205 & 263 & 264 \\
D & N & S\end{array}$ & $\begin{array}{ccccc}331 & 336 & 390 & 391 & 392 \\
F & F & P & G & F\end{array}$ & $\begin{array}{cc}455 & 458 \\
\mathrm{H} & \mathrm{A}\end{array}$ \\
\hline Lac & $\mathrm{F} \overline{\bar{P}} \mathrm{~A}$ & $\underline{\bar{D}} \mathrm{~N} \quad \mathrm{~T}$ & $\overline{\underline{F}} \overline{\bar{F}} \bar{P} \quad \bar{G} A$ & $\underline{\bar{H}} \underline{\bar{A}}$ \\
\hline ?O & $\mathrm{F} \overline{\mathrm{P}} \mathrm{F}$ & $D A F$ & $\bar{E} \quad \bar{P} \quad \bar{G} \quad F$ & $\underline{\mathrm{H}} \underline{\mathrm{A}}$ \\
\hline
\end{tabular}

Figure 5. Structural alignment of the parental binding pocket sequences. The alignment is represented as a cartoon: OB-1, gray; Lac3, red; 3PO, black. Residues involved in the catalytic pocket are highlighted as sticks and the T1Cu is depicted as a blue sphere, with $\mathrm{X}$ defined as a variable residue. Model of the OB-1 laccase based on the high resolution structure of Trametes trogii laccase (PDB entry $2 \mathrm{HRG}$ ), sharing $96 \%$ sequence identity with OB-1. Model of the Lac3 laccase based on crystal structure of Trametes sp. AH28-2, sharing $77 \%$ sequence identity with Lac3 (PDB entry 3KW7) and the model of $3 \mathrm{PO}$ laccase based on crystal structure of the PcL (PDB entry 2XYB). The images and alignments were generated and analyzed with the PyMOL Molecular Visualization System (http://pymol.org).

Depending on how the SCHEMA blocks combine with each other, synergies, incompatibilities, or neutral effects on the catalytic cavity could be observed. To illustrate this, we chose clones $\mathrm{BBBC}, \mathrm{B}^{\mathrm{C}} \mathrm{BBC}$, and $\mathrm{CBBC}$ that have very different $\mathrm{SA}$ or OCM oxidizing activity relative to the common closest homologue, despite only differing in block 1 (Figure 3, 4). Our structural alignment identified the 162-164 loop in block 1 as responsible for this effect, contributing to the variation in activity between the three chimeras, Supplementary Figure S6. Both $\mathrm{B}^{\mathrm{C}} \mathrm{BBC}$ and $\mathrm{CBBC}$ showed enhanced oxidation of $\mathrm{SA}$, in which loop 162-164 only came from 3PO, Figures 3, 4, 5. Conversely, there was no improvement in chimera BBBC, whose loop 162-164 comes from Lac3. The only difference in this loop between the three chimeras was at position 164, where there is an Ala or Phe residue from Lac3 or 3PO, respectively. Hence, the A164F substitution seems to have an important effect on the oxidation of SA. By contrast, we observed the opposite effect when comparing the oxidation of OCM by these three chimeras. Thus, while the activity of $\mathrm{BBBC}$ was $\sim 1.7$-fold better than that of the parental type,
$\mathrm{B}^{\mathrm{C}} \mathrm{BBC}$ and $\mathrm{CBBC}$ retained only roughly $60 \%$ of this activity, highlighting the correlation between an Ala instead of a Phe at position 164 and a more efficient oxidation of OCM. Although shifting substrate specificity was not the primary goal of our screen, the different oxidation patterns found among the chimeras, along with the trade-off in activity displayed by some of the variants highlights the potential of SCHEMA-RASPP structure guided recombination in vivo to modulate the substrate preferences of promiscuous enzymes.

pH Stability of Thermostable Laccase Chimeras. In addition to elevated temperatures, industrial processes are often performed under extreme $\mathrm{pH}$ conditions, which may decrease the activity and stability of enzymes. Optimum $\mathrm{pH}$ activity of fungal laccases is generally between 2 to 5 , $\mathrm{pHs}$ at which they are not very stable for extended periods. On the other hand, fungal laccases possess good storage stability at alkaline $\mathrm{pH}$, although they do not show activity due to the reversible binding of hydroxide ions to the $\mathrm{T} 2 / \mathrm{T} 3$ site. $^{37}$ Considering their stronger activity at acidic pHs, a critical aspect of laccase performance is endurance in harsh acidic conditions. In order to examine the $\mathrm{pH}$ stability of the chimeras, we selected the 5 most thermostable and active variants $\left(A A A^{B} C, C B B C, B^{C} B B C, A B B C\right.$, and $\left.B B B C\right)$, which were incubated at different $\mathrm{pHs}$ and their residual ABTS activity was measured at $\mathrm{pH}$ 4.0. As expected, at neutral and basic $\mathrm{pHs}$ both the chimeras and the parental types were very stable, conserving $80-100 \%$ of residual ABTS activity, Supplementary Figure S7. With a gradual increase in the acidity of the environment, the two most thermostable chimeras $\left(\mathrm{AAA}^{\mathrm{B}} \mathrm{C}\right.$ and $\left.\mathrm{CBBC}\right)$ displayed a significant stronger $\mathrm{pH}$ stability than any of the parents. After $72 \mathrm{~h}$ at $\mathrm{pH} 2.0$, the $\mathrm{AAA}^{\mathrm{B}} \mathrm{C}$ clone retained almost $70 \%$ of its activity, whereas the OB-1 variant, its closest parent, was practically inactive, Figure 6A. A similar effect was observed when comparing CBBC to its closest parent, Lac3, with an 8-fold improvement at $\mathrm{pH} 2.0$ after $72 \mathrm{~h}$, Figure $6 \mathrm{~A}$. Of the 3 parental types, $3 \mathrm{PO}$ exhibited the highest acidic $\mathrm{pH}$ stability, such that the increasing contribution of SCHEMA blocks from $3 \mathrm{PO}$ to the corresponding chimeras is beneficial to their $\mathrm{pH}$ stability. This is especially true for the SCHEMA block C1, which was gradually incorporated into the chimeras (from $\mathrm{BBBC}$ to $\mathrm{B}^{\mathrm{C}} \mathrm{BBC}$ and finally, to $\mathrm{CBBC}$ ), with a concomitant progressive increase of stability at $\mathrm{pH} 2.0$, Figure $6 \mathrm{~B}$. It is noteworthy that similar influence for the $\mathrm{C} 1$ block was earlier evidenced in the description of the thermostabilization of these three chimeric proteins, Figure 3. Moreover, the acid stability of $\mathrm{AAA}^{\mathrm{B}} \mathrm{C}$ and $\mathrm{CBBC}$ perfectly complements their remarkable thermal stability and activity, which makes them robust biocatalysts for industrial uses.

\section{CONCLUSION}

We generated a family of thermostable chimeric laccases by SCHEMA-RASPP structure guided recombination in vivo, an approach not yet applied to laccase engineering. SCHEMAdesigned protein blocks of three different laccases enabled chimeric laccases to be created by minimizing the disruption of the folded structure at the same time as in vivo shuffling, and assembly in yeast allowed recombination between and within the SCHEMA blocks, enriching the sequence and functional diversity of the chimeric library. This strategy proved to be extremely useful, to enhance not only thermal stability, but also stability at acidic $\mathrm{pH}$ and activity on different substrates, properties that were not under selection. By distributing 
A

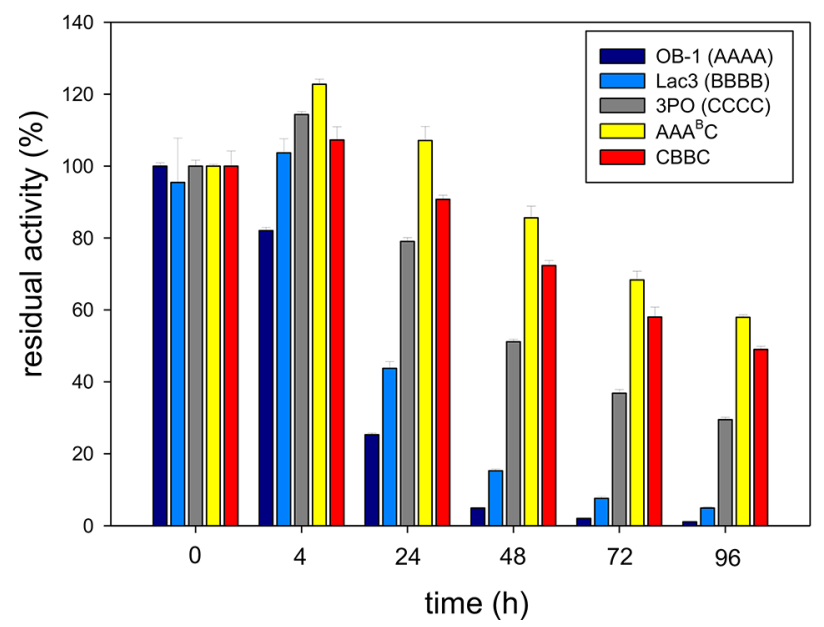

B

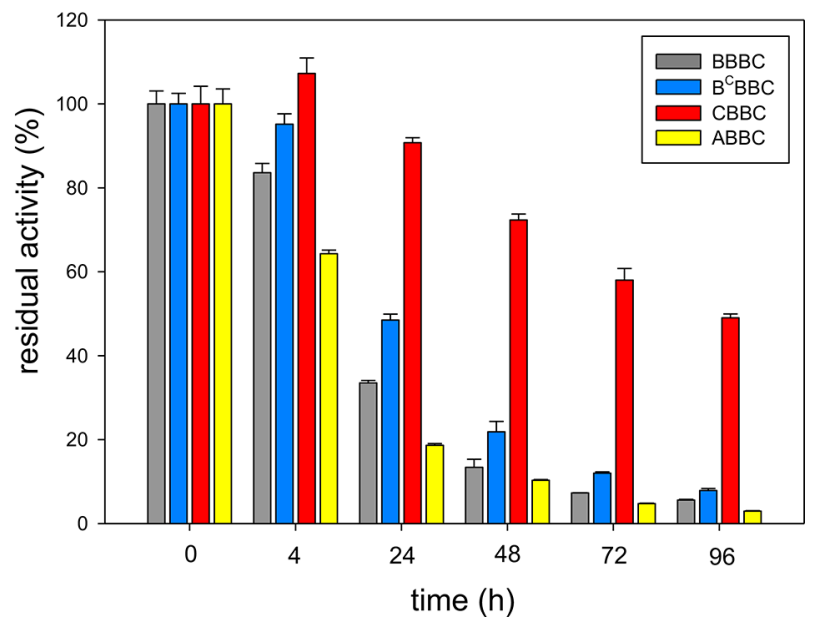

Figure 6. Enzyme stability at $\mathrm{pH}$ 2.0. (A) Comparison between the parental types and the two most stable chimeras. (B) Comparison between chimeras that only differ in block 1 . Laccases variants were incubated for $0,4,24,48,72$, and $96 \mathrm{~h}$ at $\mathrm{pH} 2.0$. Residual activity after each time was measured with $3 \mathrm{mM}$ ABTS in $100 \mathrm{mM}$ sodium phosphate/citrate buffer $\mathrm{pH}$ 4.0. Laccase activity was normalized to the highest activity at time 0 , and each point and standard deviation is derived from three independent measurements.

residues in different SCHEMA blocks, we managed to explore sequence-function relationships of chimeric laccases, and to identify specific residues influencing substrate oxidation. Significantly, the shuffling within blocks provided relevant information about the contribution of SCHEMA blocks to the biochemical properties of the chimeras. This collection of stable laccase chimeras represents an excellent starting point for future adaptive evolution endeavors. Given the structural complexity of laccases, the success obtained here by bringing together computational SCHEMA-RASPP and in vivo recombination also paves the way to engineer other structurally complex proteins.

\section{MATERIAL AND METHODS}

Materials. ABTS (2,2'-azino-bis(3-ethylbenzothiazoline-6sulfonic acid)), DMP (2,6-dimethoxyphenol), VLA (violuric acid), OCM (IV potassium octacyanomalybdate), GUA (guaiacol), SA (sinapic acid), and yeast transformation kit were purchased from Sigma-Aldrich/Merck (Darmstadt, Germany). The high-fidelity DNA polymerase PfuUltra was acquired from Agilent. S. cerevisiae strain BJ5465 was from LGC Promochem (Barcelona, Spain), while Escherichia coli XL2-Blue competent cells were from Stratagene (La Jolla, CA, USA). Zymoprep yeast plasmid miniprep kit and Zymoclean Gel DNA Recovery Kit were from Zymo Research (Orange, CA, USA). The NucleoSpin Plasmid kit was purchased from Macherey-Nagel (Düren, Germany). The restriction enzymes (BamHI, XhoI) were from New England Biolabs (Hertfordshire, UK). Oligonucleotides were synthesized by Metabion (Bayern, Germany). All chemicals were reagent-grade purity.

Culture Media. The selective expression medium (SEM) contained filtered yeast nitrogen base $(100 \mathrm{~mL}, 6.7 \%)$, filtered yeast synthetic drop-out medium supplement without uracil (100 mL, $19.2 \mathrm{~g} / \mathrm{L})$, filtered $\mathrm{KH}_{2} \mathrm{PO}_{4}$ buffer $(\mathrm{pH}$ 6.0, $67 \mathrm{~mL}, 1$ $\mathrm{M})$, filtered galactose $(111 \mathrm{~mL}, 20 \%)$, absolute ethanol (31.6 $\mathrm{mL})$, filtered chloramphenicol $(1 \mathrm{~mL}, 25 \mathrm{~g} / \mathrm{L})$, filtered $\mathrm{CuSO}_{4}$ $(1 \mathrm{~mL}, 1 \mathrm{M})$, and $\mathrm{ddH}_{2} \mathrm{O}$ (to $1000 \mathrm{~mL}$ ). Sterile minimal medium contained $100 \mathrm{~mL} 6.7 \%$ filtered yeast nitrogen base, $100 \mathrm{~mL} 19.2 \mathrm{~g} / \mathrm{L}$ filtered yeast synthetic drop-out medium supplement without uracil, $100 \mathrm{~mL}$ filtered $20 \%$ raffinose, 700 $\mathrm{mL} \mathrm{ddH}_{2} \mathrm{O}$, and $1 \mathrm{~mL} 25 \mathrm{~g} / \mathrm{L}$ filtered chloramphenicol. SC drop-out plates contained $100 \mathrm{~mL} 6.7 \%$ filtered yeast nitrogen base, $100 \mathrm{~mL} 19.2 \mathrm{~g} / \mathrm{L}$ filtered yeast synthetic drop-out medium supplement without uracil, $20 \mathrm{~g}$ autoclaved bacto agar, $100 \mathrm{~mL} \mathrm{20 \%}$ filtered glucose, $1 \mathrm{~mL} 25 \mathrm{~g} / \mathrm{L}$ filtered chloramphenicol, and $\mathrm{ddH}_{2} \mathrm{O}$ to $1000 \mathrm{~mL}$. Sterile expression medium contained $720 \mathrm{~mL}$ autoclaved $\mathrm{YP}, 67 \mathrm{~mL} 1 \mathrm{M}$ filtered

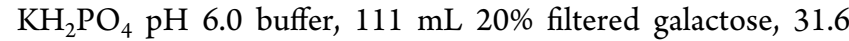
$\mathrm{mL}$ absolute ethanol, $1 \mathrm{~mL} 25 \mathrm{~g} / \mathrm{L}$ filtered chloramphenicol, 2 $\mathrm{mL} 1 \mathrm{M}$ filtered $\mathrm{CuSO}_{4}$, and $\mathrm{ddH}_{2} \mathrm{O}$ to $1000 \mathrm{~mL}$. YP medium contained $10 \mathrm{~g}$ yeast extract, $20 \mathrm{~g}$ peptone, and $\mathrm{ddH}_{2} \mathrm{O}$ to 650 $\mathrm{mL}$. YPD solution contained $10 \mathrm{~g}$ yeast extract, $20 \mathrm{~g}$ peptone, $100 \mathrm{~mL} \mathrm{20 \%} \mathrm{sterile} \mathrm{glucose,} 1 \mathrm{~mL} 25 \mathrm{~g} / \mathrm{L}$ chloramphenicol, and $\mathrm{ddH}_{2} \mathrm{O}$ to $1000 \mathrm{~mL}$. Luria-Bertani (LB) medium was prepared with $5 \mathrm{~g}$ yeast extract, $10 \mathrm{~g}$ peptone, $10 \mathrm{~g} \mathrm{NaCl}, 100$ $\mathrm{mg}$ ampicillin, and $\mathrm{ddH}_{2} \mathrm{O}$ to $1000 \mathrm{~mL}$.

Protein Modeling. Structural alignment of catalytic pocket residues was made using a model of OB-1 laccase based on high resolution structure of Trametes trogii laccase (PDB entry $2 \mathrm{HRG}),{ }^{35}$ sharing $96 \%$ sequence identity with OB-1, a model of Lac3 Trametes sp. laccase based on crystal structure of Trametes sp. AH28-2, sharing $77 \%$ sequence identity with Lac3 (PDB entry 3KW7), ${ }^{38}$ and a model of 3PO laccase based on crystal structure of the PcL (PDB entry 2XYB). Homology models were built using the SWISS-MODEL Web server. ${ }^{39}$ The structural alignment and images were generated and analyzed by PyMOL Molecular Visualization System (http:// pymol.org).

SCHEMA-RASPP Library Design. SCHEMA-RASPP was used to design the 4-block contiguous recombination library of the three parent laccases (OB-1, 3PO, and Lac3) that minimizes the library-average disruption of protein structure. ${ }^{21,40}$ An alignment of mature parental sequences (lacking their respective signal sequences) was generated in Clustal Omega ("parental alignment"). A separate alignment of the mature OB-1 sequence with the sequence extracted from the OB-1 homology model was also generated in Clustal Omega ("PDB alignment"). The parental and PDB alignments, the 
OB-1 homology model (PDB file), the desired number of crossovers $($ xo $=3)$, and a minimal number of mutations per block $(\min =20)$ were used as inputs for SCHEMA-RASPP calculations. The RASPP output is a list of SCHEMA libraries, with each library defined by a set of cross over points and annotated with average $E$ and $m$ values. To facilitate homologous recombination between fragments with minimal modification of the parental sequences, we developed an additional algorithm to score each of these libraries and the corresponding crossover points for homology levels between the three parental laccases ("add_scores" algorithm). We assessed multiple library designs by the $E$ and $m$ values, homology scores, and visualization on the OB-1 homology model. Ultimately we selected a library that was well balanced between homology at the crossover points, modulation of the $\mathrm{Cu}$ binding sites, structural conservation, a minimal number of blocks, and a minimal $E$ value. The library design was made using software packages for calculating SCHEMA energies openly available at http://cheme.che.caltech.edu/groups/fha/ Software.htm. The add_scores algorithm is available in the Supporting Information.

Comparison of Chimera Assembly Methods on SCHEMA Disruption Energy and Mutation Rate.

RASPP curves were generated for unmutated, mature laccase sequences. Eight potential SCHEMA libraries were selected such that trivial (relatively small) blocks were not considered. One of these libraries had an excellent combination of multiple properties (see main Materials and Methods) and was ultimately assembled through homologous recombination. To facilitate homologous recombination, the parental sequences were mutated at desired crossover points to provide at least 33 bp of homology. This is expected to decrease the number of mutations possible through recombination (the $m$ value) as well as the disruption of the chimeric protein structure relative to the parents (the $E$ value), though the ultimate effect on the $E$ value will depend on if the areas mutated for increased homology participate in contacts that can be disrupted through recombination. To further explore the effect of the chimera assembly method on $\mathrm{m}$ and $E$ values, eight selected libraries were designed (only in silico) for homologous recombination, golden gate assembly, and direct DNA synthesis. For homologous recombination, 33-39 bp of homology was engineered at the crossover points indicated by the unmutated parents RASPP curve; a new parental alignment was made; SCHEMA contacts, $E$, and $m$ values were calculated for each library. Note that new parents were designed for each of eight libraries. For golden gate assembly, the parents were not mutated for increased homology, but the crossover points were shifted away from the sites indicated by RASPP to the nearest site with four base pairs of homology (required by golden gate assembly). For each library, $E$ and $m$ values were recalculated at the new cross over points. Library generation through direct DNA synthesis represents an ideal situation that yields $E$ and $m$ values calculated via RASPP.

Chimeric Library Creation in S. cerevisiae. The parental types OB-1, 3PO and Lac3 were obtained as described elsewhere. ${ }^{5,6,25}$ To allow the in vivo assembly of SCHEMA blocks, specific crossover events were promoted between blocks. To do so, SCHEMA blocks were amplified with primers that generate overlapping areas of $\sim 40$ bp flanking each block, Supplementary Table S2. Overlapping areas with the linearized PjRocC30 plasmid were also included to allow the reparation of an autonomously replicating vector upon transformation in yeast.

All oligonucleotides used to amplify SCHEMA blocks are indicated in Supplementary Table S2. All 12 PCR reactions were carried out in a final volume of $50 \mu \mathrm{L}$ containing $3 \%$ DMSO, $0.3 \mathrm{mM}$ dNTPs (0.075 mM each), $0.25 \mu \mathrm{M}$ of each primer, $0.05 \mathrm{U} / \mu \mathrm{L}$ PfuUltra DNA polymerase, and $2 \mathrm{ng} / \mu \mathrm{L}$ of template. PCR reactions were carried out on a gradient thermocycler using the following parameters: $95{ }^{\circ} \mathrm{C}$ for $2 \mathrm{~min}$ ( 1 cycle); $95{ }^{\circ} \mathrm{C}$ for $45 \mathrm{~s}, 50{ }^{\circ} \mathrm{C}$ for $45 \mathrm{~s}$, and $72{ }^{\circ} \mathrm{C}$ for $60 \mathrm{~s}$ ( 28 cycles); and $72{ }^{\circ} \mathrm{C}$ for $10 \mathrm{~min}$ ( 1 cycle). Block 1 was amplified in 3 independent PCR reactions (1 PCR for each parental type). Details of all PCR reactions are in the Supporting Information. All PCR products were loaded onto a preparative agarose gel and purified by use of the Zymoclean Gel DNA Recovery kit. Plasmid pJRoC30 was linearized using $B a m \mathrm{HI}$ and XhoI restriction enzymes. The linearized vector was loaded onto a preparative agarose gel and purified with the Zymoclean Gel DNA Recovery kit. All blocks were cloned into $S$. cerevisiae together with the linear plasmid and the whole genes were in vivo reassembled and shuffled within S. cerevisiae competent cells. The PCR products (12 fragments, $100 \mathrm{ng}$ each) were mixed with the linearized vector (400 ng) and transformed into competent cells using the yeast transformation kit (Sigma). Transformed cells were plated in SC drop-out plates and incubated for 3 days at $30{ }^{\circ} \mathrm{C}$. Colonies containing the whole autonomously replicating vector were picked and subjected to the screening assay.

Thermostability Screening Assay. The high-throughput screening assay for thermostability was adapted from GarciaRuiz et al. with some modifications. ${ }^{34}$ Individual clones were picked and inoculated in sterile 96-well plates (Greiner BioOne, GmbH, Germany), referred to as master plates, containing $200 \mathrm{~mL}$ of SEM per well. In each plate, columns number 5, 6, 7 were inoculated with the corresponding parental type, and one well (H1-control) was inoculated with $S$. cerevisiae transformed with pJRoC30-MtL plasmid (laccase without activity). Plates were sealed with parafilm to prevent evaporation and incubated at $30^{\circ} \mathrm{C}, 220 \mathrm{rpm}$, and $80 \%$ relative humidity in a humidity shaker (Minitron, Infors, Switzerland) for 3 days. The master plates were centrifuged (Eppendorf $5810 \mathrm{R}$ centrifuge, Germany) for $15 \mathrm{~min}$ at $2500 \mathrm{~g}$ and $4{ }^{\circ} \mathrm{C}$. Aliquots of the supernatants were transferred from the master plates to two replica plates with the aid of a liquid handler robotic station Freedom EVO (Tecan, Switzerland), $50 \mu \mathrm{L}$ of mixture to a thermocycler plate (Multiply PCR plate without skirt, neutral, Sarstedt, Germany) and $20 \mu \mathrm{L}$ to the initial activity plate. Thermocycler plates were sealed with thermoresistant film (Deltalab, Spain) and incubated at $70{ }^{\circ} \mathrm{C}$ using a thermocycler (MyCycler, Biorad, USA). Incubation took place for $10 \mathrm{~min}$ (so that the assessed activity was reduced $2 / 3$ of the initial activity). Afterward, thermocycler plates were placed on ice for $10 \mathrm{~min}$ and further incubated for $5 \mathrm{~min}$ at room temperature. Twenty $\mu \mathrm{L}$ of supernatants were transferred from both thermocycler and initial activity plates to new plates to estimate the initial activities and residual activities values by adding $180 \mu \mathrm{L}$ of $100 \mathrm{mM}$ citrate phosphate buffer $\mathrm{pH} 4.0$ containing $1 \mathrm{mM}$ ABTS. Plates were stirred briefly and the absorption at $418 \mathrm{~nm}\left(\varepsilon\right.$ ABTS $\left.\bullet+=36000 \mathrm{M}^{-1} \mathrm{~cm}^{-1}\right)$ was followed in kinetic mode (initial turnover rates) in the plate reader (SPECTRAMax Plus 384, Molecular Devices, Sunnyvale, CA). The same experiment was performed for both the initial activity plate and residual activity plate. The values were 
normalized against the OB-1 parental type (the most thermostable one) of the corresponding plate and selected variants came from the ratio between residual activities and initial activities values. To rule out the selection of false positives, three rescreenings were carried out as described before. $^{34}$

Production of Chimeras. For each selected chimera, cell pellets were resuspended by pipetting up and down and stirring. Twenty $\mu \mathrm{L}$ of resuspended mixture was transferred to $3 \mathrm{~mL}$ of minimal medium. After $48 \mathrm{~h}$ at $30{ }^{\circ} \mathrm{C}$ and $220 \mathrm{rpm}$, plasmids were extracted by Zymoprep. E. coli XL2-Blue were transformed with the Zymoprep product, plated into LB-amp agar plates and grown at overnight at $37{ }^{\circ} \mathrm{C}$. Single colonies were inoculated in $5 \mathrm{~mL} \mathrm{LB}$-amp medium and were grown at $37{ }^{\circ} \mathrm{C}$ overnight. Plasmids were extracted, transformed into $S$. cerevisiae cells and plated on SC drop-out plates. After 3 days at $30{ }^{\circ} \mathrm{C}$, single colonies were inoculated in $5 \mathrm{~mL}$ of minimal medium and incubated for $72 \mathrm{~h}$ at $30^{\circ} \mathrm{C}$ and $220 \mathrm{rpm}$. Clones were refreshed in a final volume of $5 \mathrm{~mL}$ minimal medium with an optical density $\mathrm{OD}_{600}=0.3$. After $6-8 \mathrm{~h}$ of growing $\left(\mathrm{OD}_{600}\right.$ $=1-1.5), 9 \mathrm{~mL}$ of expression medium were inoculated with 1 $\mathrm{mL}$ preculture and incubated $48 \mathrm{~h}$ at $30^{\circ} \mathrm{C}$ and $250 \mathrm{rpm}$ in a $100 \mathrm{~mL}$ flask. Growth and expression were followed by measuring the $\mathrm{OD}_{600}$ of the cultures and the activity against ABTS, as described below, until reaching the stationary phase. Cells were removed by centrifugation at $3500 \mathrm{rpm}$ and $4{ }^{\circ} \mathrm{C}$ during $15 \mathrm{~min}$, saving the supernatant for the activity and stability assays.

Kinetic Thermostability. The thermostability of the different laccase samples was estimated by assessing their half-life of inactivation time $\left(t_{1 / 2}\right)$ values using $96 / 384$ well gradient thermocyclers. Appropriate dilutions of enzymes supernatants in $20 \mathrm{mM}$ bis-tris buffer $\mathrm{pH} 6.0$ were incubated at $70{ }^{\circ} \mathrm{C}$. Aliquots of $50 \mu \mathrm{L}$ were removed after $5,15,25,35$, $55,75,95$, and $120 \mathrm{~min}$, chilled out on ice for $10 \mathrm{~min}$ and further incubated at room temperature at least for $5 \mathrm{~min}$. Afterward, residual activity was determined in kinetic mode following the ABTS assay described above $(100 \mathrm{mM}$ sodium phosphate/citrate buffer $\mathrm{pH}$ 4.0, $3 \mathrm{mM} \mathrm{ABTS}$ ). Each point and standard deviation are from three independent measurements. The half-life $\left(t_{1 / 2}\right)$ was defined as the time required by the enzyme-after incubation at $70{ }^{\circ} \mathrm{C}$ - to lose $50 \%$ of its initial activity at room temperature.

pH Stability Measurements. Supernatants of parental types and selected chimeras were incubated at different $\mathrm{pH}$ (2-9). After incubation (0, 4, 24, 48, 72, 96 h), residual activity was measured with $3 \mathrm{mM}$ ABTS in $100 \mathrm{mM}$ sodium phosphate/citrate buffer $\mathrm{pH}$ 4.0. Laccase activity was normalized to the activity value at time $=0$ for highest activity obtained. Each point and standard deviation is from three independent measurements.

Activity Assays with Different Substrates. Twenty $\mu \mathrm{L}$ of chimeras and parental types supernatants were mixed with $180 \mu \mathrm{L}$ of $100 \mathrm{mM}$ sodium phosphate/citrate buffer $\mathrm{pH} 4.0$ and the corresponding substrates ( $3 \mathrm{mM}$ ABTS, $3 \mathrm{mM}$ DMP, $10 \mathrm{mM}$ GUA, $2 \mathrm{mM}$ OCM, $0.25 \mathrm{mM} \mathrm{SA}$, and $20 \mathrm{mM}$ VLA. Reactions were performed in triplicate, and substrate oxidations were followed through spectrophotometric changes: $\varepsilon_{418} \mathrm{ABTS}=36000 \mathrm{M}^{-1} \mathrm{~cm}^{-1} ; \varepsilon_{469} \mathrm{DMP}=27500 \mathrm{M}^{-1} \mathrm{~cm}^{-1}$; $\varepsilon_{465} \mathrm{GUA}=12100 \mathrm{M}^{-1} \mathrm{~cm}^{-1} ; \varepsilon_{388} \mathrm{OCM}=1460 \mathrm{M}^{-1} \mathrm{~cm}^{-1}$; $\varepsilon_{512} \mathrm{SA}=14066 \mathrm{M}^{-1} \mathrm{~cm}^{-1} ; \varepsilon_{515} \mathrm{VLA}=98 \mathrm{M}^{-1} \mathrm{~cm}^{-1}$. Laccase activity was normalized to the closest parental type.
DNA Sequencing. Laccase genes were sequenced by GATC-Biotech. The primers used were RMLN, FS (5'ACGACTTCCAGGTCCCTGACCAAGC-3'), RS (5'TCAATGTCCGCGTTCGCAGGGA-3'), and RMLC (see Supplementary Table S2).

\section{ASSOCIATED CONTENT}

\section{Supporting Information}

The Supporting Information is available free of charge on the ACS Publications website at DOI: 10.1021/acssynbio.8b00509.

Figures S1-S7, Tables S1-S2, and Supporting Methods (SCHEMA-RASPP scripts and details of PCR reactions) (PDF)

\section{AUTHOR INFORMATION}

\section{Corresponding Author}

*E-mail: malcalde@icp.csic.es.

ORCID

Miguel Alcalde: 0000-0001-6780-7616

Notes

The authors declare no competing financial interest.

\section{ACKNOWLEDGMENTS}

We truly thank Prof. Frances H. Arnold (California Institute of Technology) for her guidance and support throughout this study. This work was funded by the European Union (Bioenergy-FP7-PEOPLE-2013-ITN-607793), the CSIC (project PIE-201580E042), and the Spanish Ministry of Economy, Industry and Competitiveness (projects BIO201343407-R.DEWRY and BIO2016-79106-R. LIGNOLUTION).

\section{REFERENCES}

(1) Rodgers, C. J., Blanford, C. F., Giddens, S. R., Skamnioti, P., Armstrong, F. A., and Gurr, S. J. (2010) Designer laccases: a vogue for high-potential fungal enzymes? Trends Biotechnol. 28, 63-72.

(2) Mate, D. M., and Alcalde, M. (2017) Laccase: a multi-purpose biocatalyst at the forefront of biotechnology. Microb. Biotechnol. 10, 1457-1467.

(3) Kunamneni, A., Camarero, S., García-Burgos, C., Plou, F. J., Ballesteros, A., and Alcalde, M. (2008) Engineering and applications of fungal laccases for organic synthesis. Microb. Cell Fact. 7, 32.

(4) Mate, D. M., and Alcalde, M. (2015) Laccase engineering: from rational design to directed evolution. Biotechnol. Adv. 33, 25-40.

(5) Mate, D., García-Burgos, C., García-Ruiz, E., Ballesteros, A. O., Camarero, S., and Alcalde, M. (2010) Laboratory evolution of highredox potential laccases. Chem. Biol. 17, 1030-1041.

(6) Camarero, S., Pardo, I., Cañas, A. I., Molina, P., Record, E., Martinez, A., Martinez, M. J., and Alcalde, M. (2012) Engineering platforms for the directed evolution of laccase from Pycnoporus cinnabarinus. Appl. Environ. Microbiol. 78, 1370-1384.

(7) Pardo, I., Vicente, A. I., Mate, D. M., Alcalde, M., and Camarero, S. (2012) Development of chimeric laccases by directed evolution. Biotechnol. Bioeng. 109, 2978-2986.

(8) Cusano, A. M., Mekmouche, Y., Meglecz, E., and Tron, T. (2009) Plasticity of laccase generated by homeologous recombination in yeast. FEBS J. 276, 5471-5480.

(9) Nakagawa, Y., Sakamoto, Y., Kikuchi, S., Sato, T., and Yano, A. (2010) A chimeric laccase with hybrid properties of the parental Lentinula edodes laccases. Microbiol. Res. 165, 392-401.

(10) Alcalde, M. (2007) Laccases: biological functions, molecular structure and industrial applications, In Industrial Enzymes (Polaina, J., and MacCabe, A. P., Eds.) pp 461-476, Springer, Dordrecht. 
(11) Jones, S. M., and Solomon, E. I. (2015) Electron transfer and reaction mechanism of laccases. Cell. Mol. Life Sci. 72, 869-883.

(12) Otey, C. R., Silberg, J. J., Voigt, C. A., Endelman, J. B., Bandara, G., and Arnold, F. H. (2004) Functional evolution and structural conservation in chimeric cytochromes P450. Chem. Biol. 11, 309-318. (13) Meyer, M. M., Hochrein, L., and Arnold, F. H. (2006) Structure-guided SCHEMA recombination of distantly related $\beta$ lactamases. Protein Eng., Des. Sel. 19, 563-570.

(14) Otey, C. R., Landwehr, M., Endelman, J. B., Hiraga, K., Bloom, J. D., and Arnold, F. H. (2006) Structure-Guided Recombination Creates an Artificial Family of Cytochromes P450. PLoS Biol. 4, e112.

(15) Li, Y., Drummond, D. A., Sawayama, A. M., Snow, C. D., Bloom, J. D., and Arnold, F. H. (2007) A diverse family of thermostable cytochrome $\mathrm{P} 450 \mathrm{~s}$ created by recombination of stabilizing fragments. Nat. Biotechnol. 25, 1051.

(16) Heinzelman, P., Snow, C. D., Wu, I., Nguyen, C., Villalobos, A., Govindarajan, S., Minshull, J., and Arnold, F. H. (2009) A family of thermostable fungal cellulases created by structure-guided recombination. Proc. Natl. Acad. Sci. U. S. A. 106, 5610-5615.

(17) Heinzelman, P., Komor, R., Kanaan, A., Romero, P., Yu, X., Mohler, S., Snow, C., and Arnold, F. (2010) Efficient screening of fungal cellobiohydrolase class I enzymes for thermostabilizing sequence blocks by SCHEMA structure-guided recombination. Protein Eng., Des. Sel. 23, 871-880.

(18) Romero, P. A., Stone, E., Lamb, C., Chantranupong, L., Krause, A., Miklos, A., Hughes, R. A., Fechtel, B., Ellington, A. D., Arnold, F. H., and Georgiou, G. (2012) SCHEMA Designed Variants of Human Arginase I \& II Reveal Sequence Elements Important to Stability and Catalysis. ACS Synth. Biol. 1, 221-228.

(19) Smith, M. A., Rentmeister, A., Snow, C. D., Wu, T., Farrow, M. F., Mingardon, F., and Arnold, F. H. (2012) A diverse set of family 48 bacterial glycoside hydrolase cellulases created by structure-guided recombination. FEBS J. 279, 4453-4465.

(20) Bedbrook, C. N., Rice, A. J., Yang, K. K., Ding, X., Chen, S., LeProust, E. M., Gradinaru, V., and Arnold, F. H. (2017) Structureguided SCHEMA recombination generates diverse chimeric channelrhodopsins. Proc. Natl. Acad. Sci. U. S. A. 114, E2624.

(21) Voigt, C. A., Martinez, C., Wang, Z.-G., Mayo, S. L., and Arnold, F. H. (2002) Protein building blocks preserved by recombination. Nat. Struct. Biol. 9, 553.

(22) Endelman, J. B., Silberg, J. J., Wang, Z.-G., and Arnold, F. H. (2004) Site-directed protein recombination as a shortest-path problem. Protein Eng., Des. Sel. 17, 589-594.

(23) Alcalde, M. (2015) Engineering the ligninolytic enzyme consortium. Trends Biotechnol. 33, 155-162.

(24) Klonowska, A., Gaudin, C., Asso, M., Fournel, A., Réglier, M., and Tron, T. (2005) LAC3, a new low redox potential laccase from Trametes sp. strain $\mathrm{C} 30$ obtained as a recombinant protein in yeast. Enzyme Microb. Technol. 36, 34-41.

(25) Mateljak, I., Tron, T., and Alcalde, M. (2017) Evolved $\alpha$-factor prepro-leaders for directed laccase evolution in Saccharomyces cerevisiae. Microb. Biotechnol. 10, 1830-1836.

(26) Heinzelman, P., Romero, P. A., and Arnold, F. H. (2013) Efficient sampling of SCHEMA chimera families to identify useful sequence elements, In Methods in Enzymology (Keating, A. E., Ed.), pp 351-368, Elsevier.

(27) Farrow, M. F., and Arnold, F. H. (2010) Combinatorial recombination of gene fragments to construct a library of chimeras. Curr. Protoc. Protein Sci. 62, 26.2.1-26.2.20.

(28) Mate, D. M., Gonzalez-Perez, D., Mateljak, I., de Santos, P. G., Vicente, A. I., and Alcalde, M. (2017) The pocket manual of directed evolution: Tips and tricks, In Biotechnology of Microbial Enzymes (Brahmachari, G., Ed.), pp 185-213, Elsevier.

(29) Molina-Espeja, P., Viña-Gonzalez, J., Gomez-Fernandez, B. J., Martin-Diaz, J., Garcia-Ruiz, E., and Alcalde, M. (2016) Beyond the outer limits of nature by directed evolution. Biotechnol. Adv. 34, 754767.
(30) Gonzalez-Perez, D., Garcia-Ruiz, E., and Alcalde, M. (2012) Saccharomyces cerevisiae in directed evolution: An efficient tool to improve enzymes. Bioengineered 3 (3), 172-177.

(31) Alcalde, M. (2010) Mutagenesis protocols in Saccharomyces cerevisiae by in vivo overlap extension, In In Vitro Mutagenesis Protocols (Braman, J., Ed.), pp 3-14, Humana Press, Totowa, NJ.

(32) Hildén, K., Hakala, T. K., and Lundell, T. (2009) Thermotolerant and thermostable laccases. Biotechnol. Lett. 31, 1117.

(33) Bloom, J. D., Labthavikul, S. T., Otey, C. R., and Arnold, F. H. (2006) Protein stability promotes evolvability. Proc. Natl. Acad. Sci. U. S. A. 103, 5869-5874.

(34) García-Ruiz, E., Maté, D., Ballesteros, A., Martinez, A. T., and Alcalde, M. (2010) Evolving thermostability in mutant libraries of ligninolytic oxidoreductases expressed in yeast. Microb. Cell Fact. 9, 17.

(35) Matera, I., Gullotto, A., Tilli, S., Ferraroni, M., Scozzafava, A., and Briganti, F. (2008) Crystal structure of the blue multicopper oxidase from the white-rot fungus Trametes trogii complexed with ptoluate. Inorg. Chim. Acta 361, 4129-4137.

(36) Pardo, I., Santiago, G., Gentili, P., Lucas, F., Monza, E., Medrano, F. J., Galli, C., Martínez, A. T., Guallar, V., and Camarero, S. (2016) Re-designing the substrate binding pocket of laccase for enhanced oxidation of sinapic acid. Catal. Sci. Technol. 6, 3900-3910.

(37) Torres-Salas, P., Mate, D. M., Ghazi, I., Plou, F. J., Ballesteros, A. O., and Alcalde, M. (2013) Widening the $\mathrm{pH}$ Activity Profile of a Fungal Laccase by Directed Evolution. ChemBioChem 14, 934-937.

(38) Ge, H., Gao, Y., Hong, Y., Zhang, M., Xiao, Y., Teng, M., and Niu, L. (2010) Structure of native laccase B from Trametes sp. AH28-2. Acta Crystallogr., Sect. F: Struct. Biol. Cryst. Commun. 66, 254-258.

(39) Waterhouse, A., Bertoni, M., Bienert, S., Studer, G., Tauriello, G., Gumienny, R., Heer, F. T., de Beer, T. A P., Rempfer, C., Bordoli, L., Lepore, R., and Schwede, T. (2018) SWISS-MODEL: homology modelling of protein structures and complexes. Nucleic Acids Res. 46, W296-W303.

(40) Smith, M. A., and Arnold, F. H. (2014) Designing libraries of chimeric proteins using SCHEMA recombination and RASPP, In Directed Evolution Library Creation. Methods in Molecular Biology, Methods and Protocols (Gillam, E., Copp, J., and Ackerley, D., Eds.), pp 335-343, Springer, New York. 